\title{
EFFECTS OF EXERCISE ON PULMONARY FUNCTION TESTS: A COMPARATIVE STUDY BETWEEN ATHLETES AND NON-ATHLETES IN NEPALESE SETTINGS NB Mahotra ${ }^{1 *}$, TM Amatya ${ }^{2}$, BSJB Rana ${ }^{1}$, D Banstola ${ }^{1}$
}

\author{
${ }^{1}$ Department of Clinical Physiology, Maharajgunj Medical Campus, Institute of Medicine, Kathmandu. \\ ${ }^{2}$ College of Medicine, Nepal Army Institute of Health Sciences, Kathmandu. \\ *Correspondence to: Dr Narayan Bahadur Mahotra, Department of Clinical Physiology, Maharajgunj Medical Campus, Institute of Medicine, Maharajgunj, \\ Kathmandu. Email: narayanmahotra@gmail.com.
}

\begin{abstract}
Due to regular exercises, athletes tend to have an increase in pulmonary functions when compared to non exercising individuals, especially when the exercise is strenuous. Intensity and severity of sports engaged in by the athletes determines the extent of strengthening of the inspiratory muscles with a resultant increase in the lung volumes and capacities. Pulmonary parameters like tidal volume and forced vital capacity are significantly higher in athletes than in non athletes. $A$ cross sectional comparative study was carried out in national sports council, Tribhuvan army club and institute of medicine, Kathmandu, Nepal. The athletes were footballers from Tribhuvan army club and sprinters from national sports council. The non-athletes were medical students from the institute of medicine, Kathmandu. Data were collected after performing spirometry and mean values were compared between athletes and non-athletes. Pulmonary functions were assessed based on forced vital capacity (FVC), forced expiratory volume in 1 second (FEV1) and peak expiratory flow rate (PEFR) expressed as percent predicted for the age, sex, height, weight and race. Spirometry was performed in 169 subjects, out of which 84 were athletes and 85 were non-athletes. Athletes had a significantly superior FVC $(P=0.00)$ compared to non-athletes. FEV1 was also recorded significantly higher in athletes than in non-athletes $(P=0.023)$. Athletes have better pulmonary function tests than non-athletes because exercise in athletes strengthens the muscles of respiration.
\end{abstract}

Key words: Athletes, Non-athletes, Pulmonary function tests, Spirometry.

\section{INTRODUCTION}

Depending on the purpose of the exercises, there are various types of exercises like aerobic exercise, strength exercise and flexibility exercise. If we are trying to improve stamina and circulatory system, aerobic exercise would benefit us. A brisk walk, dancing, swimming, playing tennis, stationary bicycle are some examples of aerobic exercises. If we are trying to build muscle, strength exercise would be the proper choice. Flexibility exercises also called stretching, help keep joints flexible and reduce chances of injury during other activities. So, whatever our goals are, we will be able to find the type of exercise appropriate for us. Due to regular exercises, pulmonary parameters like tidal volume and forced vital capacity are significantly higher in athletes than in non athletes. ${ }^{1,2}$ Training improves the physical working capacity. An athlete has a resting bradycardia, a greater $\mathrm{VO}_{2}$ max and higher spirometric values when compared to non athletes. ${ }^{3}$

\section{METHODS}

A cross sectional comparative study was carried out for a period of six months from April 2009 to September 2009 in National sports council, Nepal army Rajdal Gan complex and the Institute of Medicine, Kathmandu after obtaining ethical approval from Institutional review board of institute of medicine. Athletes were from the national sports council and from Tribhuvan army club, Kathmandu who were practicing regular exercises and nonathletes were medical students from the institute of medicine, who were not practicing regular exercises. Non probability purposive sampling was adopted for this study. Pulmonary function was assessed based on FEV1, FVC and PEFR expressed 
as percent predicted for the age, sex, height, weight and race. Smokers and the subjects with American Thoracic Society (ATS) questionnaires suggestive of any active respiratory disorders and cardiovascular disorders were excluded from the study. The Spirometry was conducted in sitting position using MIR SPIROLAB II spirometer based on ATS recommendations. The mean temperature and relative humidity in the city of Kathmandu was $22^{\circ} \mathrm{C}$ and $96 \%$ respectively. The athletes were aged between 18 to 40 years, mean age 25.71 ( \pm 4.55 ) years and mean weight and mean height were 62.63 ( \pm 8.91) and $167.41( \pm 5.69) \mathrm{cm}$ respectively. The non-athletes were aged between 18 to 29 years, mean age 20.68 ( \pm 1.52 ) years and mean height and weight were $165.41( \pm 9.18) \mathrm{cm}$ and 55.31 ( \pm 8.13) kg respectively. Pulmonary parameters were analyzed in the form of percentage predicted for the age, sex, height, weight and race. Body temperature and pressure saturation (BTPS) was autocorrected by the spirometer. Unpaired t test was used for the comparison of athletes and non-athletes and data analysis was done with SPSS statistics version 13.

\section{RESULTS}

Spirometry was conducted in 169 subjects, out of which 84 were athletes and 85 were non-athletes. When comparing the mean values of FVC, FEV1 and PEFR between the athletes and non-athletes, athletes had a significantly superior FVC $(P=0.00)$ compared to non-athletes. Similarly, FEV1 was also significantly higher in the athletes compared to non-athletes $(P=0.023)$. But interestingly $P E F R$ value was recorded lower in athletes than in non-athletes $(P=0.66)$

Table1. T-test comparing non-athletes and athletes on FVC\% predicted, FEV\% predicted, and PEFR\% predicted ( $n=85$ non-athletes and 84 athletes)

\begin{tabular}{|l|l|l|l|l|l|l|}
\hline Variable & \multicolumn{1}{|c|}{ Category } & \multicolumn{1}{c|}{ Mean } & Std. Dev. & \multicolumn{1}{c|}{$\boldsymbol{T}$} & \multicolumn{1}{c|}{$\boldsymbol{d f}$} & \multicolumn{1}{c|}{$\boldsymbol{P}$} \\
\hline \multirow{2}{*}{ FVC\% } & Non-athletes & 93.64 & 10.36 & -5.20 & 167 & 0.00 \\
\cline { 2 - 7 } & Athletes & 103.40 & 13.76 & & & \\
\hline \multirow{2}{*}{ FEV1\% } & Non-athletes & 100.96 & 10.79 & -2.29 & 167 & 0.023 \\
\cline { 2 - 8 } & Athletes & 105.35 & 13.91 & & & \\
\hline \multirow{2}{*}{ PEFR\% } & Non-athletes & 103.49 & 13.47 & 0.43 & 167 & 0.66 \\
\cline { 2 - 8 } & Athletes & 102.50 & 16.06 & & & \\
\hline
\end{tabular}

\section{DISCUSSION}

Involvement in certain physical activities or sports could help in respiratory muscle strengthening and improvement in pulmonary function. Pursuing a physical activity or sports which could help in achieving efficient lung function (FVC, FEV1) is an essential preventive strategy in this busy age when prevalence of sedentary lifestyles is increasing and so are the associated lifestyle disorders. ${ }^{4,5}$ The objective of this study was to determine whether the pulmonary function tests of athletes were better compared to the people who had sedentary life styles. The result of this research supports the previous works done by various researchers all over the world indicating that pulmonary function tests in athletes are better compared to non athletes. Although athletes had significantly better lung functions as compared to non athletes, there is

also some concern of exercise induced asthma and prevalence of bronchospasm in endurance athletes especially due to chronic hyperventilation of cold dry air mediated bronchial dysfunction. ${ }^{6}$ It is common knowledge that regular use of a muscle groups leads to its hypertrophy. Training for strength leads to increase in the size of the muscles involved. Further as a result of strength training, there is an increase in the production of contractile proteins such as actin and myosin. The increased amounts of these proteins increases the cross bridges available for generating force during muscle contraction. Muscle biopsy has shown that after endurance training there is a significant increase in capillary to muscle fibers ratio. 


\section{CONCLUSION}

Athletes have better pulmonary functions tests than non-athletes because every exercise helps to strengthen the muscles of the body including muscles of the chest. So, the people should be involved in physical activities or sports for better pulmonary function and for better health. The results of this study could be used for the selection of better sportsmen and also in recruitment of army and police personnel as well as in the services where there is need of better physical health.

\section{REFERENCES}

1. Kippelen P, Caillaud C, Robert E, Connes P. Effects of endurance training on lung function: $A$ one year study. Br J Sports Med 2005;39:617-621.

2. Adegoke OA, Arogundade O. The effect of Chronic exercise on lung function and Basal metabolic rate in some Nigerian Athletes. African Journal of Biomedical Research 2002;5:9-11.

3. Saltin B, Grimby G. Physiological analysis of middle aged and old former Athletes: Comparison with still active athletes of the same ages. Circulation. 1968;38:1104-1115.

4. Prakash S, Meshram S, Ramtekkar U. Athletes, Yogis and Individuals with sedentary life styles. Do their lung functions differ? Indian J Physiol Pharmacol 2007;51(1):76-80.

5. Hagberg JM, Yerg II, Seals DR. Pulmonary Function in Young and Older Athletes and Untrained Men. J Appl Physiol 1988;65(1):101105.

6. Rundell $\mathrm{KW}$, Spiering BA. Inspiratory stridor in Elite Athletes. Chest 2003;123:468-474. 